\begin{tabular}{|c|c|c|}
\hline$p_{e}$ & $=P$ at equilibrium & {$\left[\mathrm{kmol} / \mathrm{m}^{3}\right]$} \\
\hline$T$ & $=$ absolute temperature & {$[\mathrm{K}]$} \\
\hline$t$ & $=$ reaction time & [h] \\
\hline$V$ & $=$ volume of substrate solution & {$[R]$} \\
\hline$V_{a}$ & $=$ apparent reaction rate & {$[\mathrm{mol} / \mathrm{hr} \cdot \mathrm{g}-\mathrm{gel}]$} \\
\hline$V_{a m}$ & $=$ apparent maximum reaction rate & {$[\mathrm{mol} / \mathrm{hr} \cdot \mathrm{g}-\mathrm{gel}]$} \\
\hline$V_{a m}^{*}$ & $=V_{a m}$ at $1 \mathrm{kmol} / \mathrm{m}^{3}$ of $S_{0}$ & {$[\mathrm{~mol} / \mathrm{hr} \cdot \mathrm{g}-\mathrm{gel}]$} \\
\hline$V_{a m}^{* *}$ & $=V_{a m}$ at $1 \mathrm{kmol} / \mathrm{m}^{3}$ of $S_{0}$ at $37^{\circ} \mathrm{C}$ & {$[\mathrm{mol} / \mathrm{hr} \cdot \mathrm{g}-\mathrm{gel}]$} \\
\hline$Y$ & $=$ productivity of L-aspartic acid & {$[\mathrm{mol} / \mathrm{h}]$} \\
\hline
\end{tabular}

Literature Cited

1) Chibata, I., T. Tosa, T. Sato and T. Mori: "Immobilized
Enzymes Research and Development," p. 148, Kodansha, Tokyo (1978).

2) Pitcher Jr., W. H.: "Advances in Biochemical Engineering," Vol. 10, p. 1, Springer-Verlag, Berlin Heidelberg (1978).

3) Takamatsu, S., K. Yamashita and A. Sumi: J. Ferment. Technol., 58, 129 (1980).

4) Takamatsu, S., M. Ueba and K. Yamashita: J. Chem. Eng. Japan, in press.

5) Weetall, H. H.: "Biotechnological Applications of Proteins and Enzymes," p. 103, Academic Press, New York (1977).

(Presented at the 44th Annual Meeting of The Society of Chemical Engineers, Japan, at Tokyo, April 1979.)

\title{
THE EFFECT OF DILUENT IN THE LIQUID-LIOUID EXTRACTION OF COBALT AND NICKEL USING ACIDIC ORGANOPHOSPHORUS COMPOUNDS
}

\author{
ISAO KOMASAWA, TSUTAO OTAKE AND YOSHIMI OGAWA \\ Department of Chemical Engineering, Faculty of Engineering Science, \\ Osaka University, Toyonaka 560
}

Key Words: Metal Extraction, Cobalt Nickel Separation, Diluent Effect, Modifier, Acidic

Organophosphorus Extractant, High Metal Loading

\begin{abstract}
The effect of the diluent in the extraction of $\mathrm{Co}, \mathrm{Ni}$ and $\mathrm{Na}$ from nitrate media with di(2-ethylhexyl)phosphoric acid (HDEHP) and 2-ethylhexylphosphonic acid mono-2-ethylhexyl ester (EHPNA) was studied, using non-polar hydrocarbons and polar solvents with different electron-donor strength as diluents. The effect caused by the diluent-extractant interaction was found to be relatively weak, owing to the great tendency toward self-association of the extractant. With the higher alcohols as diluent, however, the diluent can coordinate with the extracted metal complex in the Co/HDEHP system. Furthermore, it substitutes for the neutral extractant molecule in the nickel complex. This substitution and the stabilization of the associated water molecules by the alcohol diluent enhances nickel extraction, achieving the same performance as in cobalt extraction. Successively larger aggregated metal complexes appear in all diluents tested, to differing extent depending on the nature of the diluent. Equilibrium formulations were determined for various combinations of metal and diluent.
\end{abstract}

\section{Introduction}

Processes for solvent extraction of metals have been developed for specially selected combinations of extractant and diluent, sometimes making use of a modifier. The diluent then is not only a carrier for the extractant and extracted metal complex, but also a participant in the extraction process. The effect of the diluent is essentially an organic-phase reaction or interaction due to at least one of following two factors. ${ }^{8)}$

(a) Interaction with the extractant molecules, which affects the activity of the extractant and

Received July 1, 1983. Correspondence concerning this articie should be addressed to I Komasawa. Y, Ogawa is now with Daicel Chemicals Industries Ltd., Sakai 590 changes the extraction performance of the extractant.

(b) Interaction with the extracted metal complex, which may change the composition of the complex through coordination and/or substitution of the diluent molecules.

A typical example of category (a) is the extraction of copper with a hydroxyoxime extractant. ${ }^{6}$ The hydroxyoxime has an oxime-hydroxyl group that behaves as an electron-acceptor (hydrogen-donor). The copper distribution ratio is lower by four to five orders of magnitude in electron-donor diluents ( $n$ donor compounds such as alcohols and ketones) than in non-polar hydrocarbons, without changing the composition of the extracted species. 
Acidic organophosphorus compounds have a common and pronounced tendency toward forming aggregates in organic solution which exist in dimeric form at moderate concentrations. Furthermore, these have a $\mathrm{P} \rightarrow 0$ group which belongs to the $n$-donor solvent class. The interaction between extractant and diluent can, therefore, be expected to be moderate or relatively weak, owing to the self-association of the extractant. However, the extracted metal complex contains one or more neutral extractant molecules. This inclusion may be regarded as one of solvation by the extractant.

Extraction of metals with di(2-ethylhexyl)phosphoric acid and 2-ethylhexylphosphonic acid mono2-ethylhexyl ester were studied in previous works, ${ }^{4,5}$ using only non-polar hydrocarbons as diluents. In practical extraction systems, however, the use of a modifier, especially higher alcohols, to prevent third-phase formation is generally known.

The present study was therefore undertaken to extend the previous results and to fully evaluate the nature of the interaction with the diluent for this extraction system. Several polar solvents, especially higher alcohols, were employed as diluents in addition to non-polar hydrocarbon solvents. The extraction performance and equilibrium formulations for cobalt, nickel and sodium were measured for single-diluent as well as for mixed-diluent systems. The electronic spectra of the organic solutions were also studied.

\section{Experiments}

The extractants, di(2-ethylhexyl)phosphoric acid (HDEHP) and 2-ethylhexylphosphonic acid mono-2ethylhexyl ester (EHPNA) were purified from commercial reagents supplied by Daihachi Chemicals Ind. Co., Ltd., Osaka, Japan, following the procedure described previously. ${ }^{4,5)}$ All inorganic chemicals and solvents such as $n$-heptane, xylene, toluene, benzene, nitrobenzene, $n$-butylether, methyl- $n$-heptylketone and 2-ethylhexyl alcohol were supplied by Wako Chemical Ltd., as analytically pure reagent grade. Industrial-grade (bp $211.0-218.5^{\circ} \mathrm{C}$ ) isodecanol was provided by Nissan Chemical Ind. Water and all solvents except xylene and isodecanol were purified by simple distillation.

The procedure for measurement of the extraction equilibria of cobalt, nickel and sodium has already been described. ${ }^{4,5)}$ The water content in the organic solution was determined by Karl-Fisher titration. Electronic spectra of the organic solution containing metal complex were obtained in the wave length range $320-840 \mathrm{~nm}$ using a Shimadzu UV-200 spectrophotometer. The organic samples were identical to those for the measurement of extraction equilibria of metal.

\section{Results}

\subsection{Electronic spectra of the organic phase}

Xylene and 2-ethylhexyl alcohol were selected as example of non-polar and polar solvents with high electron-donor strength, respectively. Typical examples of the spectra of these diluents are illustrated in Figs. 1(a) and (b). The location and intensity of the absorbance maxima in the spectra suggest the structure of the metal complex in the organic solution. ${ }^{1,10,12)}$ All nickel complexes are yellowish-green in color. Spectra of Ni-HDEHP/xylene $\left(\varepsilon_{\max }=\right.$ $0.73 \mathrm{~m}^{2} / \mathrm{mol}$ at $\left.396 \mathrm{~nm}\right), \mathrm{Ni}-\mathrm{HDEHP} / 2$-ethylhexyl alcohol $\left(\varepsilon_{\max }=0.76\right.$ at $\left.396 \mathrm{~nm}\right)$, Ni-EHPNA/xylene $\left(\varepsilon_{\max }=0.85\right.$ at $\left.408 \mathrm{~nm}\right)$ and Ni-EHPNA/2-ethylhexyl alcohol $\left(\varepsilon_{\max }=0.85\right.$ at $\left.396 \mathrm{~nm}\right)$ suggest that they are all typical of octahedral coordination.

In the case of the Co-HDEHP complex, the deep blue colour in xylene changes to pink in 2-ethylhexyl alcohol. The spectrum in xylene $\left(\varepsilon_{\max }=27.2\right.$ at $626 \mathrm{~nm}$ ) reveals a typical tetrahedral symmetry, whilst that in 2-ethylhexyl alcohol $\left(\varepsilon_{\max }=0.70\right.$ at $\left.520 \mathrm{~nm}\right)$ has an octahedral symmetry. The hydroxyl-containing diluent is likely to interact with the Co-HDEHP complex and convert it to octahedral symmetry through the coordination of the alcohol molecules with the metal.

The Co-EHPNA complex in xylene has a deep blue colour and its spectrum $\left(\varepsilon_{\max }=29.0\right.$ at $\left.632 \mathrm{~nm}\right)$ suggests tetrahedral symmetry as seen in the case of HDEHP. The complex in 2-ethylhexyl alcohol has a dark purple colour and its spectrum $(\varepsilon=1.45$ at $544 \mathrm{~nm}, \varepsilon_{\max }=1.50$ at $580 \mathrm{~nm}$ and $\varepsilon=1.48$ at $628 \mathrm{~nm}$ ) suggests that the complex still retains the features of tetrahedral symmetry in the higher alcohols.

Sato and Nakamura ${ }^{10)}$ have determined the structures of the HDEHP complexes in the absence of $n$ hexane diluent to be $\mathrm{Co}$ :tetrahedral and $\mathrm{Ni}$ : octahedral. The present data with a xylene diluent system corroborate their findings. Very recently, Preston has studied the effect of a range of organic-phase additives on the stereochemistry of metal complexes and the resulting cobalt-nickel separation, using HDEHP and EHPNA as extractants. ${ }^{9)}$ The results obtained from the electronic spectra studies, as a whole, support the present results.

\subsection{Extraction equilibria of metals for low loading of the organic solution}

The results for the extraction of nickel and cobalt with HDEHP are shown, respectively, in Figs. 2(a) and (b), in terms of a plot of $D\left[\mathrm{H}^{+}\right]^{2}$ against the concentration of HDEHP. The results for EHPNA are plotted in Figs. 3(a) and (b). For cobalt, straight lines with a slope of 2 are obtained for both extractants and for all diluents employed. The overall extraction equilibria may be expressed as follows: 

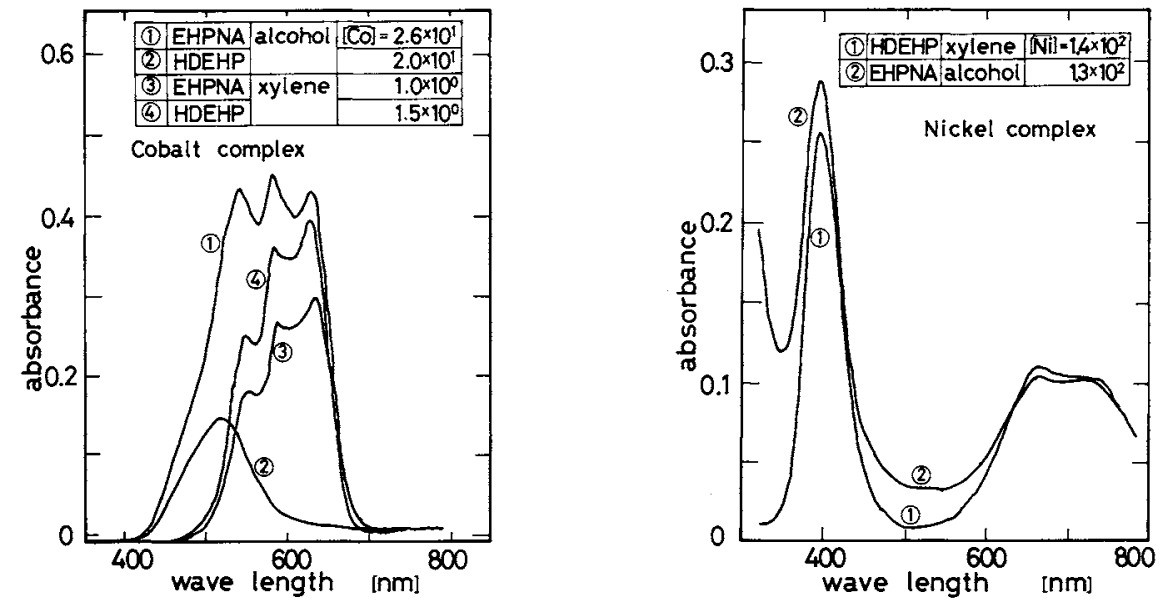

Fig. 1(a) and (b). Electronic spectra of metal complexes in xylene and 2-ethylhexyl alcohol.
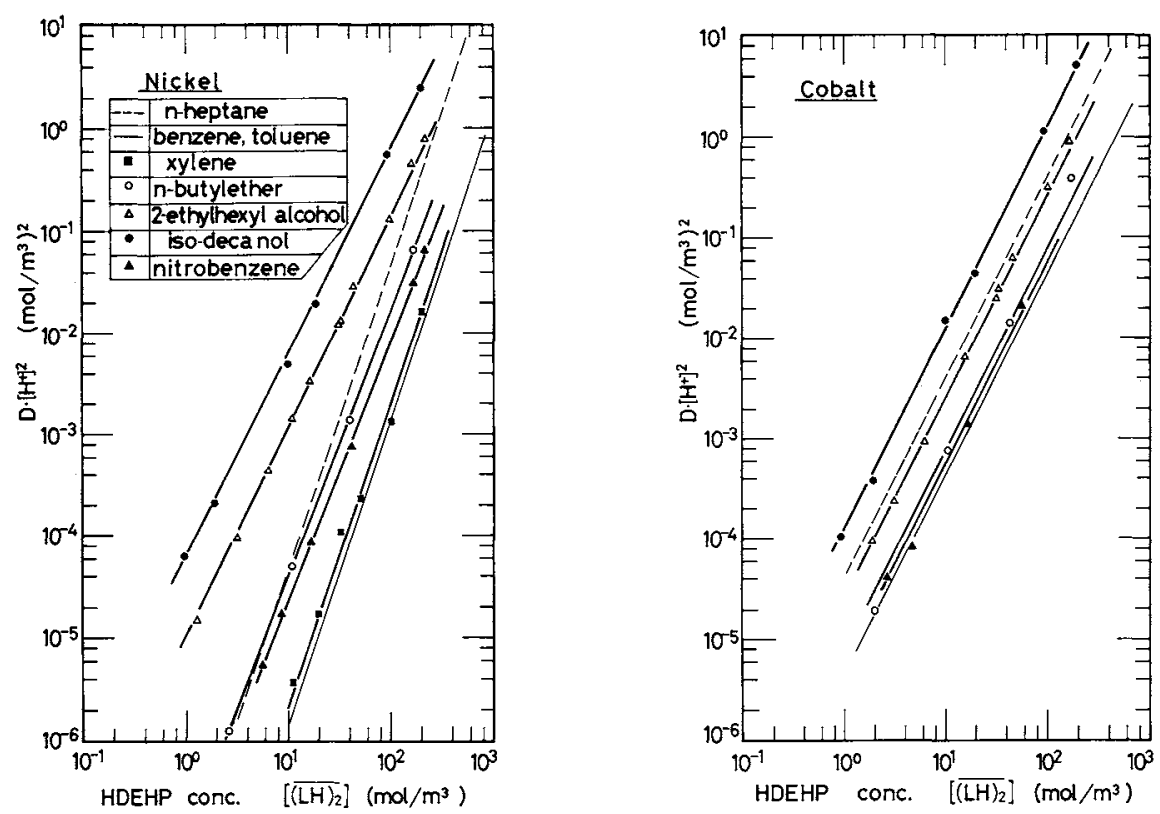

Fig. 2(a) and (b). Diluent effect in the extraction of nickel and cobalt with di(2-ethylhexyl)phosphoric acid.
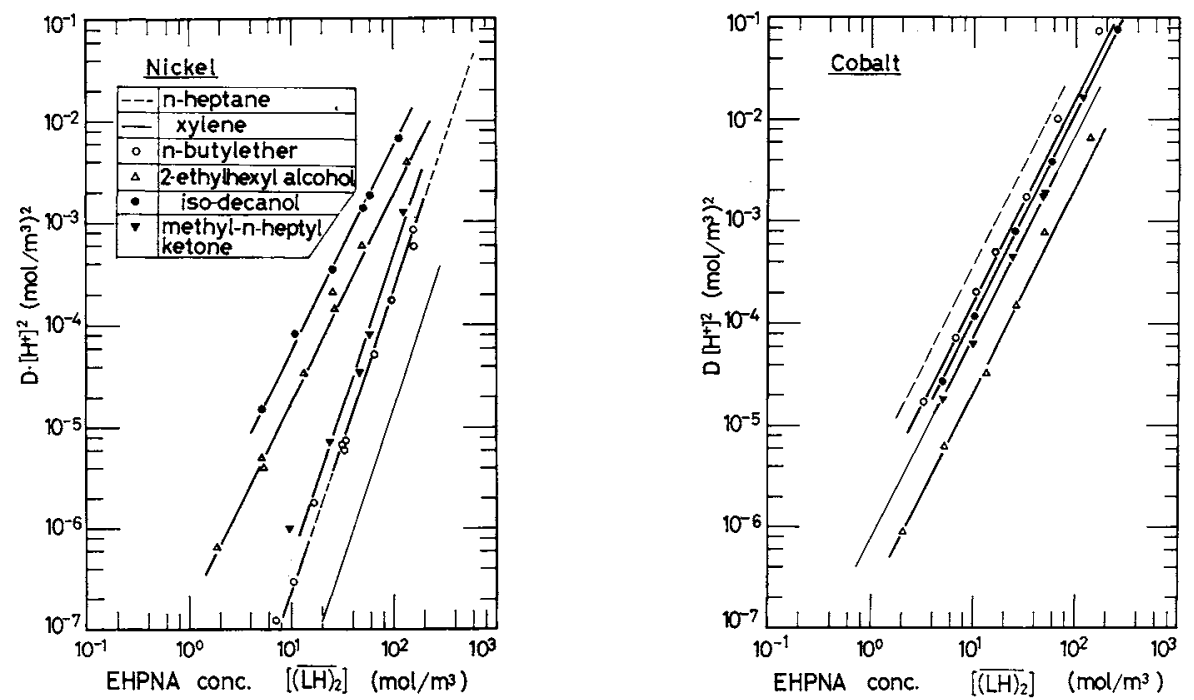

Fig. 3(a) and (b). Diluent effect in the extraction of nickel and cobalt with 2-ethylhexylphosphonic acid mono-2-ethylhexyl ester. 


$$
\begin{aligned}
& \mathrm{Co}^{2+}+2 \overline{(\mathrm{LH})_{2}} \rightleftharpoons \overline{\mathrm{CoL}_{2}(\overline{\mathrm{LH}})_{2}}+2 \mathrm{H}^{+} \\
& K_{\text {ex }}=\left[\overline{\mathrm{CoL}_{2}(\overline{\mathrm{LH}})_{2}}\right]\left[\mathrm{H}^{+}\right]^{2} /\left[\mathrm{Co}^{2+}\right]\left[\overline{(\mathrm{LH})_{2}}\right]^{2}
\end{aligned}
$$

The corresponding extraction constants are summarized in Table 1. These are not spread widely, in sharp contrast to the results obtained in the hydroxyoxime extractant system. ${ }^{6}$ )

For the HDEHP, the extraction constant decreased in the order isodecanol $>n$-heptane $>2$-ethylhexyl alcohol $>n$-butylether $>$ nitrobenzene $>$ toluene and benzene, whilst for the EHPNA the order is $n$ heptane $>n$-butylether $>$ isodecanol $>$ methyl- $n$ heptylketone $>$ xylene $>$ 2-ethylhexyl alcohol. The constant in 2-ethylhexyl alcohol is very close to that in $n$-heptane for the case of HDEHP extractant. For EHPNA, on the other hand, the constant is the smallest for the diluents employed. In the HDEHP/ 2-ethylhexyl alcohol system, the complex is transformed to octahedral symmetry, whereas the tetrahedral structure is preserved in the case of EHPNA. Such a synergism compensates for the adverse effect caused by the extractant-diluent interaction, so that there is only a slight depression of extraction performance.

For nickel extraction, the situation is rather complicated. With non-polar solvents such as $n$-heptane, benzene, toluene and xylene as diluent, straight lines with a slope of 3 are obtained and the extraction equilibrium is expressed as ${ }^{5)}$

$$
\begin{aligned}
& \mathrm{Ni}^{2+}+3 \overline{(\mathrm{LH})_{2}} \rightleftharpoons \overline{\mathrm{NiL}_{2} 2(\mathrm{LH})_{2}}+2 \mathrm{H}^{+} \\
& K_{\mathrm{ex}}=\left[\overline{\mathrm{NiL}_{2} 2(\mathrm{LH})_{2}}\right]\left[\mathrm{H}^{+}\right]^{2} /\left[\mathrm{Ni}^{2+}\right]\left[\overline{(\mathrm{LH})_{2}}\right]^{3}
\end{aligned}
$$

In relatively weak electron-donors, such as nbutylether and nitrobenzene, the slope of the lines is lowered to 2.6 in the case of HDEHP, but remains at 3.0 for EHPNA. The Ni-HDEHP complex seems to be more affected by the diluent than the Ni-EHPNA complex, as found in cobalt extraction. For the higher alcohols, the slope of the lines decreases to 2.0 for both extractants, and the extraction equilibrium is:

$$
\begin{aligned}
& \mathrm{Ni}^{2+}+2 \overline{(\mathrm{LH})_{2}} \rightleftharpoons \overline{\mathrm{NiL}_{2}(\mathrm{LH})_{2}}+2 \mathrm{H}^{+} \\
& K_{\mathrm{ex}}=\left[\overline{\mathrm{NiL}_{2}(\overline{\mathrm{LH}})_{2}}\right]\left[\mathrm{H}^{+}\right]^{2} /\left[\mathrm{Ni}^{2+}\right]\left[\overline{(\mathrm{LH})_{2}}\right]^{2}
\end{aligned}
$$

The nickel complexes exhibit octahedral coordination and contain water in both the diluents, xylene and 2ethylhexyl alcohol, as will be shown later. The nickel ion, with a coordination number of 6 , tends to retain several water molecules in the first coordination sphere. The higher alcohols are likely to have a greater ability to replace the water molecule than the present neutral extractants and also to have the ability to stabilize the associated water. Alcohol thus enhances nickel extraction. It can therefore be inferred that the extracted species is present as $\overline{\mathrm{NiL}_{2} 2(\mathrm{LH})_{2}}$ in the non-polar hydrocarbons, and as $\overline{\mathrm{NiL}_{2}(\mathrm{LH})_{2} \mathrm{Al}}$ in the higher alcohols (Al:alcohol). A similar variation in the composition of the metal species with the diluent has been observed in the extraction of europium and terbium with dioctylphosphoric acid. ${ }^{3)}$

Preston has found that nickel extraction is enhanced by the addition of isodecanol to xylene diluent and suggested that the following substitution reaction may occur in the organic phase. ${ }^{9)}$

$$
\overline{\mathrm{NiL}_{2} 2(\mathrm{LH})_{2}}+2 \overline{\mathrm{B}} \rightleftharpoons \overline{\mathrm{NiL}_{2}(\mathrm{LH})_{2} \mathrm{~B}_{2}}+\overline{(\mathrm{LH})_{2}}
$$

where $\overline{\mathrm{B}}$ denotes isodecanol. This agrees with the present study in that the diluent substitutes with a neutral extractant molecule in the complex.

\subsection{Water content in the organic phase}

Data giving the water content of the organic solution containing the EHPNA complexes are plotted in Fig. 4 in terms of the loading ratio, where $A\left[\overline{\mathbf{H}_{2} \mathrm{O}}\right]$ indicates the difference between the water content of the orgainc solution and that of the solution without metal loading. Only the cobalt-EHPNA complex in xylene does not contain water. The ratios of water to metal molecules in the complex are found to be 4-6 for nickel in xylene and 5-8 for both nickel and cobalt in 2-ethylhexyl alcohol. This indicates that the associated water molecules are likely to be stabilized by alcohol molecules. In the case of sodium, the molar ratio of water to sodium is 1.3 when $[\overline{\mathrm{Na}}] /\left[\overline{\left(\mathrm{LH}_{2}\right]_{\mathrm{f}}}=\right.$ 0.1 , and increases to $8-10$ for $[\overline{\mathrm{Na}}] /\left[\overline{(\mathrm{LH})_{2}}\right]_{\mathrm{f}}=1.0$.

The transfer of water into HDEHP benzene solution has been found to increase linearly with conversion of the acid to its sodium salt. ${ }^{7)}$ Sato et al. ${ }^{10,11)}$ found that HDEHP complexes saturated with cobalt do not contain associated water molecules, whilst the nickel complex does contain two water molecules per nickel ion. These results have been obtained for HDEHP complexes saturated with metals in the absence of $n$-hexane or kerosene diluent.

\subsection{Extraction equilibria for high loading of the or- ganic phase}

The extraction equilibrium formulations, Eqs. (1)-(6), are valid in the range of low loading of the extractant. Several series of runs were made, in which organic metal concentration was varied. The apparent extraction constants, obtained on the basis of Eqs. (2), (4) and (6), are plotted against the loading ratio in Figs. 5(a) and (b). In $n$-heptane diluent, the values remain constant up to $0.08-0.10$ for cobalt and 0.02 for nickel. The ranges for the xylene diluent system were found to extend up to 0.08 for cobalt and 0.008 for nickel. ${ }^{5}$ With 2-ethylhexyl alcohol as diluent, the ranges expand to $0.15-0.20$ for both cobalt and nickel, as expected from the electronic spectra study. No significant difference is seen between the extraction performances of cobalt and nickel. The addition of $10 \%$ alcohol to xylene lowers the extraction con- 
Table 1. Extraction constants for monomeric species and aggregated species

\begin{tabular}{|c|c|c|c|c|c|c|c|c|}
\hline & \multicolumn{2}{|r|}{ HDEHP } & \multicolumn{6}{|c|}{ EHPNA } \\
\hline & \multirow{2}{*}{$\begin{array}{l}\mathrm{Co} \\
K_{\mathrm{ex}}^{*}\end{array}$} & \multirow{2}{*}{$\begin{array}{l}\mathrm{Ni} \\
K_{\mathrm{ex}}\end{array}$} & \multicolumn{2}{|c|}{ Co } & \multicolumn{2}{|c|}{$\mathrm{Ni}$} & \multicolumn{2}{|c|}{$\mathrm{Na}$} \\
\hline & & & $K_{\mathrm{ex}}^{*}$ & $K_{\mathrm{p}}^{*}$ & $K_{\mathrm{ex}}$ & $K_{\mathrm{p}}$ & $K_{\text {ex }}$ & $K_{\mathrm{p}}$ \\
\hline$n$-Heptane & $4.0 \times 10^{-5}$ & $4.5 \times 10^{-8} \mathrm{~m}^{3} / \mathrm{mol}$ & $3.4 \times 10^{-6}$ & $6.0 \times 10^{-6}$ & $\begin{array}{c}2.4 \times 10^{-10} \\
\mathrm{~m}^{3} / \mathrm{mol}\end{array}$ & $\begin{array}{c}1.0 \times 10^{-10} \\
\mathrm{~m}^{3} / \mathrm{mol}\end{array}$ & - & - \\
\hline Xylene & - & $2.0 \times 10^{-9} \mathrm{~m}^{3} / \mathrm{mol}$ & $7.5 \times 10^{-7}$ & $1.5 \times 10^{-7}$ & $\begin{array}{c}1.5 \times 10^{-11} \\
\mathrm{~m}^{3} / \mathrm{mol}\end{array}$ & $\begin{array}{c}1.5 \times 10^{-11} \\
\mathrm{~m}^{3} / \mathrm{mol}\end{array}$ & $\begin{array}{l}1.8 \times 10^{-9} \\
\mathrm{~m}^{3} / \mathrm{mol}\end{array}$ & $\begin{array}{l}3.2 \times 10^{-8} \\
\left(\mathrm{~m}^{3} / \mathrm{mol}\right)^{1 / 2}\end{array}$ \\
\hline $\begin{array}{l}\text { 2-Ethylhexyl } \\
\text { alcohol }\end{array}$ & $2.6 \times 10^{-5}$ & $1.1 \times 10^{-5}[-]$ & $2.0 \times 10^{-7}$ & $7.6 \times 10^{-8}$ & $2.0 \times 10^{-7}$ & $6.2 \times 10^{-8}$ & - & 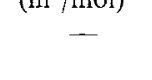 \\
\hline $\begin{array}{l}90 \% \text { Xylene }+10 \% \\
\text { alcohol }\end{array}$ & - & - & $2.0 \times 10^{-7}$ & $6.2 \times 10^{-8}$ & - & - & $\begin{array}{l}2.2 \times 10^{-9} \\
\mathrm{~m}^{3} / \mathrm{mol}\end{array}$ & $\begin{array}{l}3.3 \times 10^{-8} \\
\left(\mathrm{~m}^{3} / \mathrm{mol}\right)^{1 / 2}\end{array}$ \\
\hline Isodecanol & $1.3 \times 10^{-4}$ & $6.2 \times 10^{-5}[-]$ & $1.2 \times 10^{-6}$ & - & $\begin{array}{l}5.5 \times 10^{-7} \\
{[-]}\end{array}$ & & & \\
\hline Benzene, toluene & $4.5 \times 10^{-6}$ & $1.5 \times 10^{-9} \mathrm{~m}^{3} / \mathrm{mol}$ & - & - & - & & & \\
\hline Nitrobenzene & $6.3 \times 10^{-6}$ & $2.6\left(7.0 \times 10^{-8}\right)^{* *}$ & - & - & - & & & \\
\hline Ketone & - & - & $7.5 \times 10^{-7}$ & - & $\begin{array}{c}5.0 \times 10^{-10} \\
\mathrm{~m}^{3} / \mathrm{mol}\end{array}$ & & & \\
\hline Ether & $7.4 \times 10^{-6}$ & $2.6\left(1.1 \times 10^{-7}\right)^{* *}$ & $1.6 \times 10^{-6}$ & - & $\begin{array}{c}1.8 \times 10^{-10} \\
\mathrm{~m}^{3} / \mathrm{mol}\end{array}$ & & & \\
\hline
\end{tabular}

* For cobalt: the unit is dimensionless for all combinations.

** Slope (Intercept at $[\overline{\mathrm{LH}}]_{2}=1.0 \mathrm{~mol} / \mathrm{m}^{3}$ ).

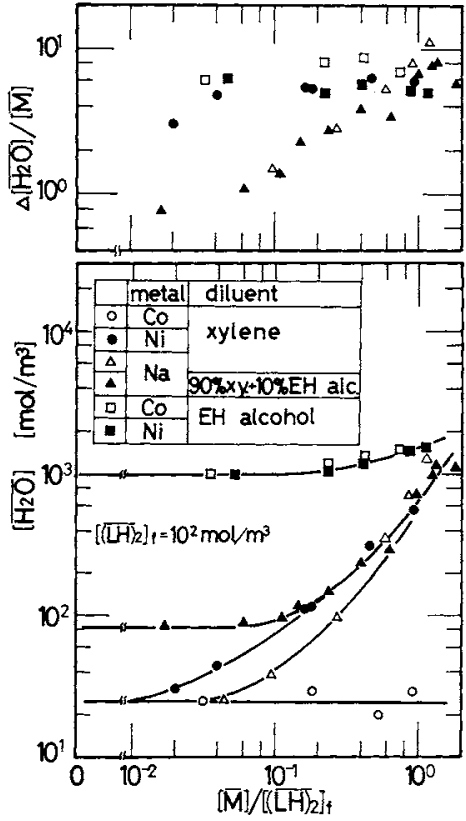

Fig. 4. Effect of metal loading ratio on water content of solution.

stant for cobalt to the identical value found with a single diluent based on alcohol.

With increase in loading ratio, successively larger aggregated metal complexes appear, and the extraction equilibria for a xylene diluent are ${ }^{\text {s) }}$

$$
\begin{aligned}
\mathrm{Co}^{2+} & +2 \overline{(\mathrm{LH})_{2}} \stackrel{K_{\mathrm{ex}}}{\rightleftharpoons} \overline{\mathrm{CoL}_{2}\left(\overline{\mathrm{LH})_{2}}\right.}+2 \mathrm{H}^{+} \\
\mathrm{Co}^{2+} & +\overline{\left(\mathrm{CoL}_{2}\right)_{n-1}(\mathrm{LH})_{2}} \\
& +\overline{\left(\overline{\mathrm{LH})_{2}}\right.} \stackrel{K_{\mathrm{p}}}{\rightleftharpoons} \overline{\left(\mathrm{CoL}_{2}\right)_{n}(\mathrm{LH})_{2}}+2 \mathrm{H}^{+}
\end{aligned}
$$

$$
\begin{aligned}
& K_{\mathrm{p}}= \frac{\left[\overline{\left[\left(\mathrm{CoL}_{2}\right)_{n}(\mathrm{LH})_{2}\right]\left[\mathrm{H}^{+}\right.}\right]^{2}}{\left[\mathrm{Co}^{2+}\right]\left[\overline{\left(\mathrm{CoL}_{2}\right)_{n-1}\left(\overline{\mathrm{LH})_{2}}\right]\left[\overline{(\mathrm{LH})_{2}}\right]}\right.} \\
& \mathrm{Ni}^{2+}+3 \overline{\left(\overline{\mathrm{LH})_{2}} \stackrel{K_{\text {ex }}}{\rightleftharpoons} \overline{\mathrm{NiL}_{2} 2(\mathrm{LH})_{2}}+2 \mathrm{H}^{+}\right.} \\
& \mathrm{Ni}^{2+}+\overline{\left(\mathrm{NiL}_{2}(\mathrm{LH})_{2}\right)_{n-1}(\mathrm{LH})_{2}} \\
&+2 \overline{(\mathrm{LH})_{2}} \rightleftharpoons \overline{K_{\mathrm{p}}} \overline{\left(\mathrm{NiL}_{2}(\mathrm{LH})_{2}\right)_{n}(\mathrm{LH})_{2}}+2 \mathrm{H}^{+} \\
& K_{\mathrm{p}}= \frac{\left[\overline{\left.\left(\mathrm{NiL}_{2}(\mathrm{LH})_{2}\right)_{n}(\mathrm{LH})_{2}\right]\left[\mathrm{H}^{+}\right]^{2}}\right.}{\left[\mathrm{Ni}^{2+}\right]\left[\overline{\left.\left(\mathrm{NiL}_{2}(\overline{\mathrm{LH}})_{2}\right)_{n-1}(\mathrm{LH})_{2}\right]\left[\overline{\mathrm{LH})_{2}}\right]^{2}}\right.}
\end{aligned}
$$

These are expected to be applied to a $n$-heptane diluent system. For a 2-ethylhexyl alcohol diluent system, the formulations for both cobalt and nickel are assumed to be:

$$
\begin{aligned}
& \mathrm{M}^{2+}+2 \overline{(\mathrm{LH})_{2}} \stackrel{K_{\mathrm{ex}}}{\rightleftharpoons} \overline{\mathrm{ML}_{2}(\mathrm{LH})_{2}}+2 \mathrm{H}^{+} \\
& \mathrm{M}^{2+}+\overline{\left(\overline{\mathrm{ML}}_{2}\right)_{n-1}(\mathrm{LH})_{2}} \\
& +\overline{(\mathrm{LH})_{2}} \stackrel{K_{\mathrm{p}}}{\rightleftharpoons} \overline{\left(\mathrm{ML}_{2}\right)_{n}(\mathrm{LH})_{2}}+2 \mathrm{H}^{+} \\
& K_{\mathrm{p}}=\frac{\left[\overline{\left(\mathrm{ML}_{2}\right)_{n}(\mathrm{LH})_{2}}\right]\left[\mathrm{H}^{+}\right]^{2}}{\left.\left[\mathrm{M}^{2+}\right] \overline{\left(\mathrm{ML}_{2}\right)_{n-1}(\mathrm{LH})_{2}}\right]\left[\overline{\left.(\mathrm{LH})_{2}\right]}\right.}
\end{aligned}
$$

Identification of the aggregated species is established on the assumption that the extraction constants are independent of the number of metal atoms, $n$, in the species. This procedure has been described previously. ${ }^{5)}$ The constants thus obtained are summarized in Table 1, together with published data. ${ }^{4,5)}$ Consequently, the possible structures of the metal species can be represented as shown in Fig. 6. The association of water molecules is represented by a 

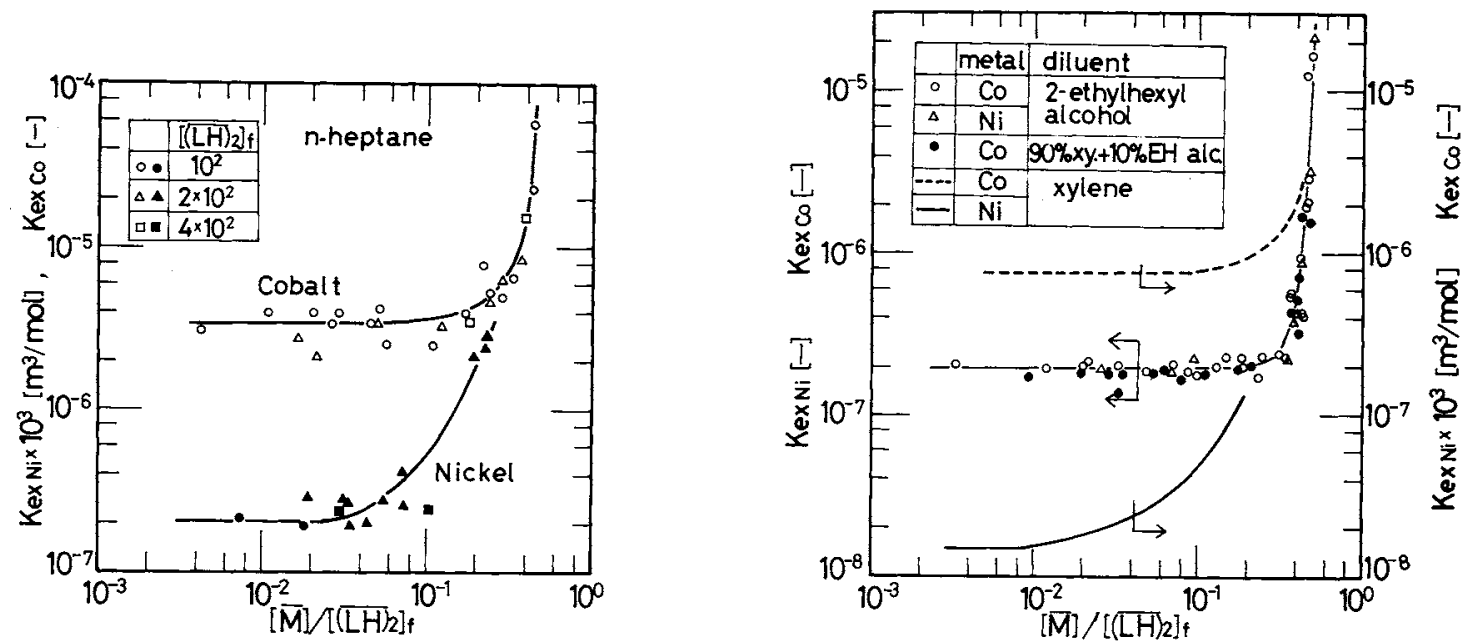

Fig. 5(a) and (b). Effect of loading ratios of EHPNA solution with cobalt and nickel in various diluents on the extraction constant obtained, assuming only the monomeric species extracted.

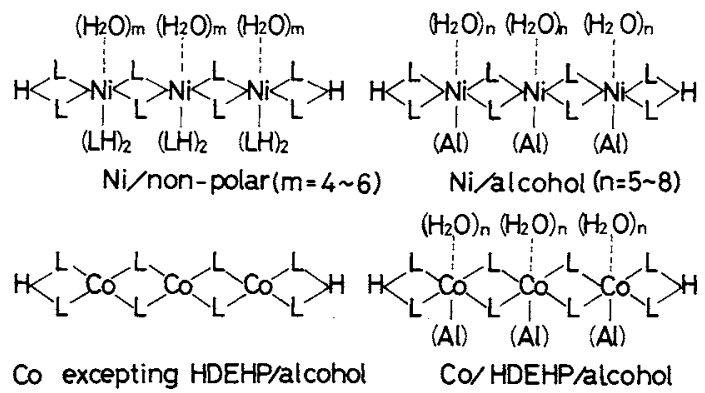

Fig. 6. Possible structures of cobalt and nickel complexes in various diluents (trimeric species).

dotted line, since the structure of the species containing water is not specified.

The present extractants were used as a mixture of acid form and their sodium or ammonium salt. The equilibrium formulation for monomeric sodium species was found to be ${ }^{5)}$ :

$$
\mathrm{Na}^{+}+2 \overline{(\mathrm{LH})_{2}} \stackrel{K_{\text {ex }}}{\rightleftharpoons} \overline{\mathrm{NaL}(3 / 2)(\mathrm{LH})_{2}}+\mathrm{H}^{+}
$$

The formulation for the aggregated species is found to be expressed as

$$
\begin{aligned}
& \mathrm{Na}^{+}+\overline{(\mathrm{NaL})_{n-1}(3 / 2)(\mathrm{LH})_{2}} \\
&+(1 / 2) \overline{(\mathrm{LH})_{2}} \stackrel{K_{\mathrm{p}}}{\rightleftharpoons(\mathrm{NaL})_{n}(3 / 2)(\mathrm{LH})_{2}}+\mathrm{H}^{+} \\
& K_{\mathrm{p}}=\frac{\overline{\left.(\mathrm{NaL})_{n}(3 / 2)(\mathrm{LH})_{2}\right]}\left[\mathrm{H}^{+}\right]}{\left[\mathrm{Na}^{+}\right] \overline{\left[(\mathrm{NaL})_{n-1}(3 / 2)(\mathrm{LH})_{2}\right]\left[\overline{(\mathrm{LH})_{2}}\right]^{1 / 2}}}
\end{aligned}
$$

The values of $K_{\mathrm{ex}}$ and $K_{\mathrm{p}}$ thus determined are also shown in Table 1. Only a slight difference is seen between the values in xylene and in a mixed diluent of $90 \%$ xylene and 10\% 2-ethylhexyl alcohol.

\section{Discussion}

To visualize the deduction made from the electronic spectra for the incorporation of the alcohol molecule into the nickel complex, measurements were also made of nickel extraction in which xylene, the host diluent, was progressively replaced by either 2-ethylhexyl alcohol or isodecanol. Interaction of the diluent with the metal complex was found to be much greater than that with the extractant, at least in the nickel extraction system. The present approach was used by Dyrssen and Kuca to identify the complexes in the extraction of uranyl ion with dibutylphosphoric acid and tri-n-butyl phosphate. ${ }^{2)}$

Two nickel complexes are assumed to be formed in a mixed diluent, as follows:

$$
\begin{aligned}
& \mathrm{Ni}^{2+}+3 \overline{(\overline{\mathrm{LH}})_{2}} \rightleftharpoons \overline{\mathrm{NiL}_{2} 2(\mathrm{LH})_{2}}+2 \mathrm{H}^{+} \\
& D_{\mathrm{X}}\left[\mathrm{H}^{+}\right]^{2}=K_{\mathrm{ex}, \mathrm{x}}\left[\overline{(\mathrm{LH})_{2}}\right]^{3}
\end{aligned}
$$

and

$$
\mathrm{Ni}^{2+}+2 \overline{(\mathrm{LH})_{2}}+\overline{\mathrm{A} 1} \rightleftharpoons \overline{\mathrm{NiL}_{2}(\mathrm{LH})_{2} \mathrm{Al}}+2 \mathrm{H}^{+}
$$

$$
D_{\mathrm{A}}\left[\mathrm{H}^{+}\right]^{2}=K_{\text {ex }, \mathrm{A}}\left[\overline{(\mathrm{LH})_{2}}\right]^{2}[\overline{\mathrm{Al}}]
$$

The net distribution ratio, $D_{O A}$, is the sum of $D_{\mathrm{X}}$ and $D_{\mathrm{A}}$, so that

$$
D_{0 \mathrm{~A}}\left[\mathrm{H}^{+}\right]^{2} /\left[\overline{(\mathrm{LH})_{2}}\right]^{3}=K_{\mathrm{ex}, \mathrm{X}}+K_{\mathrm{ex}, \mathrm{A}}[\overline{\mathrm{Al}}] /\left[\overline{(\mathrm{LH})_{2}}\right]
$$

The results are plotted, on the basis of Eq. (18), in Figs. 7(a) and (b). All the data fall reasonably well on distinct curves, from which the values of $K_{\mathrm{ex}, \mathrm{A}}$ are found to be $5.0 \times 10^{-10} \mathrm{~m}^{3} / \mathrm{mol}$ for HDEHP and $4.4 \times 10^{-12} \mathrm{~m}^{3} / \mathrm{mol}$ for EHPNA in the 2-ethylhexyl alcohol-xylene system, and $1.8 \times 10^{-9} \mathrm{~m}^{3} / \mathrm{mol}$ for HDEHP and $1.8 \times 10^{-11} \mathrm{~m}^{3} / \mathrm{mol}$ for EHPNA in the 


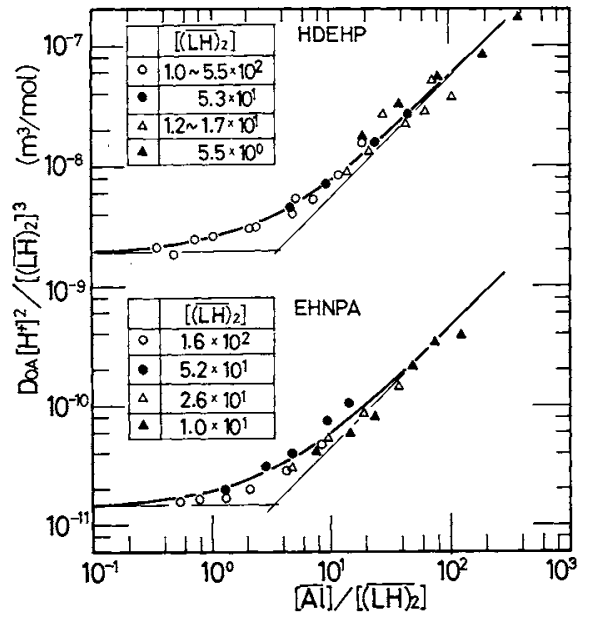

(a) 2-ethylhexyl alcohol 8 xylene

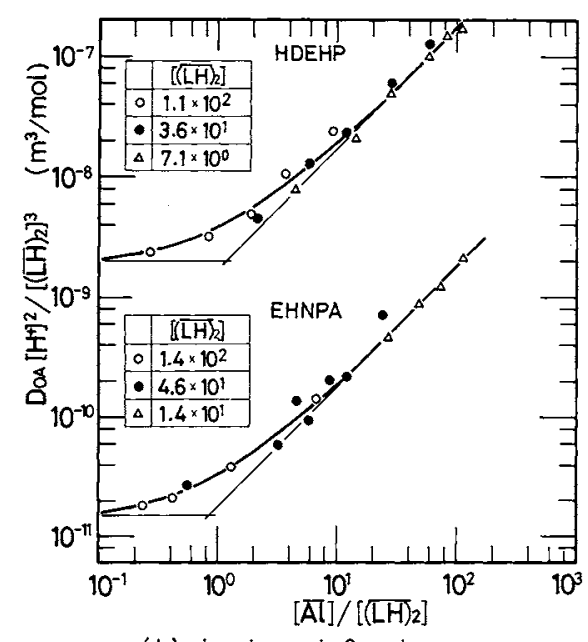

(b) iso-decanol $\&$ xylene

Fig. 7(a) and (b). Plot based on assumed formation of a substitution complex in the extraction of nickel with HDEHP and EHPNA in mixed diluent of xylene and an alcohol.

isodecanol-xylene system. The thick lines in the figures are those calculated by use of the above values and the constants $K_{\text {ex }, \mathrm{X}}=2.0 \times 10^{-9} \mathrm{~m}^{3} / \mathrm{mol}$ for HDEHP and $1.5 \times 10^{-11} \mathrm{~m}^{3} / \mathrm{mol}$ for EHPNA.

From comparison of Eq. (6) and Eq. (17), the extraction constant obtained in a single diluent of the alcohol, $K_{\mathrm{ex}}$, must be related to the constant obtained in a mixed diluent, $K_{\mathrm{ex}, \mathrm{A}}$, by

$$
K_{\mathrm{ex}}=K_{\mathrm{ex}, \mathrm{A}}[\overline{\mathrm{p}-\mathrm{Al}]}
$$

where $[\overline{\mathrm{p}}-\overline{\mathrm{Al}}]]$ is the concentration of the alcohol in the solution of its single diluent. With the approximate value of $[\overline{\mathrm{p}}-\mathrm{Al}]=6.4 \times 10^{3} \mathrm{~mol} / \mathrm{m}^{3}$ for 2-ethylhexyl alcohol and $5.3 \times 10^{3} \mathrm{~mol} / \mathrm{m}^{3}$ for isodecanol, the values of $K_{\text {ex }}$ are calculated to be $3.2 \times 10^{-6}$ [-] for HDEHP and $2.8 \times 10^{-8}$ for EHPNA in 2-ethylhexyl alcohol, and $9.5 \times 10^{-6}$ for HDEHP and $9.5 \times 10^{-8}$ for EHPNA in isodecanol. These values are very similar to those obtained for the single diluents and summarized in Table 1. Consequently, the nickel complex in the alcohol diluent can reasonably be expressed by the composition $\overline{\mathrm{NiL}_{2}(\mathrm{LH})_{2} \mathrm{Al}}$.

\section{Conclusion}

The diluent effect in the extraction of metals such as cobalt, nickel and sodium with HDEHP and EHPNA was studied, employing non-polar hydrocarbons and polar solvents, especially higher alcohols, as diluents. The following results were obtained.

1) The extractants form complexes of tetrahedral symmetry with cobalt. Only in the case of HDEHP/ alcohol can the alcohol cause coordination of the complex and transform it to an octahedral complex. The overall extraction equilibria in all diluents have been expressed by the same formulation. The diluentextractant interaction is relatively weak and therefore the range of the extraction constants is only 30 for the
HDEHP and 17 for the EHPNA extractant systems in all diluents investigated.

2) The extractants form complexes having octahedral symmetry with nickel. The alcohol diluent has the ability to substitute the neutral extractant in the complex. This brings a change in the overall extraction equilibrium formulation established by use of non-polar or weak polar diluents. In addition, the $\mathrm{Ni}$ EHPNA complex in the alcohol contains more water molecules than the complex in xylene. The incorporation of alcohol and the stabilization of the associated water molecules by the alcohol causes a considerable enhancement in nickel extraction, preventing nickel-cobalt separation in alcohol diluent.

3) With an increase in loading ratio of the organic phase, successively larger aggregated metal complexes appear even in alcohol diluent, although the range in which the monomeric species can exist is expanded to some extent. Equilibrium formulations for the aggregated species were determined for various combinations of metal and diluent. The constants thus obtained are summarized in Table 1.

\section{Nomenclature}

$D \quad=$ distribution ratio of metal $\quad[-]$

$K_{\mathrm{ex}} \quad=$ extraction constant for monomeric metal species defined by Eqs. (2), (4), (6) and (13).

$K_{\mathrm{p}} \quad=$ extraction constant for aggregated metal species defined by Eqs. (8), (10), (12) and (15).

$=$ molar extinction coefficient of organic metal complex, where concentration of complex is defined by number of metal atoms $\quad\left[\mathrm{m}^{2} / \mathrm{mol}\right]$ [ ] = concentration of species in brackets $\quad\left[\mathrm{mol} / \mathrm{m}^{3}\right]$

〈Subscript〉

$\begin{array}{ll}\mathrm{f} & =\text { initial or feed value } \\ 0 & =\text { value obtained for single diluent }\end{array}$ 
$=$ organic-phase species or organic-phase concentration

\section{Literature Cited}

1) Cotton, F. A. and G. Wilkinson: "Advanced Inorganic Chemistry," 3rd ed., p. 874 and 890 , Interscience Publishers, New York (1972).

2) Dyrssen, D. and L. Kuca: Acta Chem. Scand., 14, 1945 (1960).

3) Kolarik, Z.: "Solvent Extraction Chemistry," p. 250, ed. by D. Dyrssen, J. O. Liljenzin and J. Rydberg, North-Holland, Amsterdam (1967).

4) Komasawa, I., T. Otake and Y. Higaki: J. Inorg. Nucl. Chem., 43, 3351 (1981).

5) Komasawa, I., T. Otake and I. Hattori: J. Chem. Eng. Japan, 16, 210 (1983)

6) Komasawa, I. and T. Otake: J. Chem. Eng. Japan, 16, 377
(1983).

7) Myers, A. L., W. J. McDowell and C. F. Coleman: J. Inorg. Nucl. Chem., 26, 2005 (1964).

8) Marcus, Y. and A. S. Kertes: "Ion Exchange and Solvent Extraction of Metal Complexes," Chapter 11, Wiley, Interscience, New York (1969).

9) Preston, J. S.: Hydrometallurgy, 9, 115 (1982).

10) Sato, T. and T. Nakamura: J. Inorg. Nucl. Chem., 34, 3721 (1972).

11) Sato, T., M. Kawamura, T. Nakamura and M. Ueda: J. Appl. Chem. Biotechnol., 28, 85 (1978).

12) Yamada, S.: "Haiikagobutsu no Kozo (Structure of Coordination Compounds)," p. 125, Kagakudojin, Kyoto (1980).

(Presented at Symposium on Solvent Extraction at Hamamatsu, December 10-11, 1982.)

\title{
PRACTICAL STUDY OF A SOLVENT EXTRACTION PROCESS FOR SEPARATION OF COBALT AND NICKEL WITH 2-ETHYLHEXYLPHOSPHONIC ACID MONO-2-ETHYLHEXYL ESTER
}

\author{
ISAO KOMASAWA AND TSUTAO OTAKE \\ Department of Chemical Engineering, Faculty of Engineering Science, \\ Osaka University, Toyonaka 560
}

Key Words: Phosphonic Acid Monoester, Cobalt Nickel Separation, Metal Extraction Process, Separation Factor, Liquid Ion Exchanger, Hydrometallurgy, Scrubbing, Purification, Interfacial Tension, Third Phase Formation

\begin{abstract}
A practical study was carried out to determine the optimal operating conditions for the separation of cobalt from nickel. With non-polar solvents as diluents, no problem associated with the viscosity of the organic phase and the interfacial tension arises so long as the loading ratio of the organic phase is maintained less than 0.8 . A cobalt solution containing a nickel contamination of less than $0.005 \%$ was obtained, using single-stage extraction followed by single scrubbing. The addition of $10 \% 2$-ethylhexyl alcohol results in serious lowering of the separation factor, although it has the advantage of preventing third-phase formation during the conversion of the extractant to its sodium salt. The alkali metal hydroxide equivalent to the amount of metal to be extracted is required in the extraction. As a prospective process, a continuous extraction was carried out satisfactorily in which sodium hydroxide solution was fed into the stage together with the acid form of the extractant diluted in xylene and the aqueous feed stream.
\end{abstract}

\section{Introduction}

Alkylphosphonic acid monoester, especially 2ethylhexylphosphonic acid mono-2-ethylhexyl ester (abbreviated as EHPNA or simply LH), has been found to be a suitable reagent for the separation of cobalt from nickel in acidic sulphate or nitrate so-

\footnotetext{
Received September 1, 1983. Correspondence concerning this article should be addressed to I. Komasawa.
}

lution. EHPNA is now known to have much better features than di(2-ethylhexyl)phosphoric acid (HDEHP) for cobalt-nickel separation..$^{9-11,13)}$

The extraction of divalent metal with the acid form of EHPNA or HDEHP produces twice as many hydrogen ions as the metal extracted. Thus to permit the extraction of the desired amounts of metal, part of the extractant is converted to its sodium or ammonium salt and the aqueous phase is maintained in 